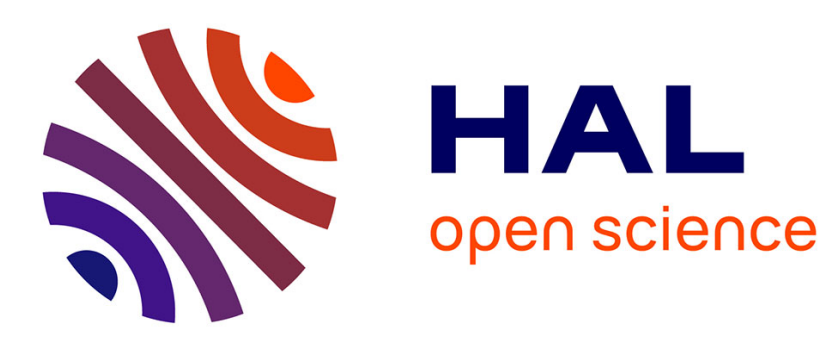

\title{
La leyenda de los Siete infantes de Salas y su enseñanza sobre solidaridad linajística
}

Georges Martin

\section{To cite this version:}

Georges Martin. La leyenda de los Siete infantes de Salas y su enseñanza sobre solidaridad linajística. e-Spania - Revue interdisciplinaire d'études hispaniques médiévales et modernes, 2012, 14, revue en ligne, sans pagination. 10.4000/e-spania.22032 . halshs-00686354v2

\section{HAL Id: halshs-00686354 \\ https://shs.hal.science/halshs-00686354v2}

Submitted on 11 Mar 2013

HAL is a multi-disciplinary open access archive for the deposit and dissemination of scientific research documents, whether they are published or not. The documents may come from teaching and research institutions in France or abroad, or from public or private research centers.
L'archive ouverte pluridisciplinaire HAL, est destinée au dépôt et à la diffusion de documents scientifiques de niveau recherche, publiés ou non, émanant des établissements d'enseignement et de recherche français ou étrangers, des laboratoires publics ou privés. 
Georges MARTIN

\title{
La leyenda de los Siete infantes de Salas y su enseñanza sobre solidaridad linajística
}

\begin{abstract}
Avertissement
Le contenu de ce site relève de la législation française sur la propriété intellectuelle et est la propriété exclusive de l'éditeur.

Les œuvres figurant sur ce site peuvent être consultées et reproduites sur un support papier ou numérique sous réserve qu'elles soient strictement réservées à un usage soit personnel, soit scientifique ou pédagogique excluant toute exploitation commerciale. La reproduction devra obligatoirement mentionner l'éditeur, le nom de la revue, l'auteur et la référence du document.

Toute autre reproduction est interdite sauf accord préalable de l'éditeur, en dehors des cas prévus par la législation en vigueur en France.
\end{abstract}

\section{revues.org}

Revues.org est un portail de revues en sciences humaines et sociales développé par le Cléo, Centre pour l'édition électronique ouverte (CNRS, EHESS, UP, UAPV).

Référence électronique

Georges MARTIN, « La leyenda de los Siete infantes de Salas y su enseñanza sobre solidaridad linajística », eSpania [En ligne], 14 | décembre 2012, mis en ligne le 18 janvier 2013, consulté le 08 mars 2013. URL : http://espania.revues.org/22032 ; DOI : 10.4000/e-spania.22032

Éditeur : CLEA (Civilisations et Littératures d'Espagne et d'Amérique du Moyen Âge aux Lumières), EA 4083 http://e-spania.revues.org

http://www.revues.org

Document accessible en ligne sur:

http://e-spania.revues.org/22032

Document généré automatiquement le 08 mars 2013.

(c) e-Spania 


\section{Georges MARTIN}

\section{La leyenda de los Siete infantes de Salas y su enseñanza sobre solidaridad linajística}

A mis amigos de Salas de los Infantes, tan atentos, generosos y entrañables La hegemonía cultural del clero fue tal a lo largo de la alta Edad Media y de la Edad Media central que a duras penas podemos saber de la cultura o de los referentes mentales de los otros componentes de la sociedad medieval. No me refiero sólo al casi ignoto campesinado: tampoco la nobleza, hasta bien entrado el siglo XIV, produjo expresiones directas y depuradas de sus valores, siendo al respecto inaugural la obra de don Juan Manuel.

(1)

No por eso ignoramos las bases de la mentalidad nobiliaria en periodos anteriores. La historiografía regia, sobre todo a partir de la primera mitad del siglo XIII, con la Historia de rebus Hispaniae de Rodrigo Jiménez de Rada ${ }^{1}$, como también, a partir de los años centrales del mismo siglo, algún componente, tan próximo al tratado como al libro de leyes, de la codificación jurídica alfonsí - la segunda de las Siete Partidas, por ejemplo- dejan transparentarse interesantes facetas de la armazón ideológica del grupo nobiliario.

Ahora bien, estas formulaciones, además de ser tardías, están moldeadas, poco o mucho, por el agente regio-clerical que media entre la realidad sociológica del grupo y su expresión textual. A quien pretende hallar huellas más inmediatas y fidedignas de la mentalidad nobiliaria y de las reglas internas de organización y funcionamiento del grupo, la heroicidad legendaria o poética -además de las prácticas (en particular matrimoniales) que se traslucen de la documentación o de las genealogías- brinda, como el folklore o la ritualidad festiva en el caso del campesinado y del pueblo de las ciudades, un fondo auténtico, rico y variado.

En España, sin embargo, el mismo agente regio-clerical que conformaba la historiografía regia fue el que dejó constancia de gran parte de este material, mediando entre el genuino producto nobiliario y su transmutación historiográfica el mal llamado proceso de "prosificación cronística"”2. Esto obliga al estudioso a desarmar las trampas de los cronistas, elaborando una herramienta crítica que permita desentrañar de la reelaboración historiográfica el sentido, la ideología y la función socio-cultural del relato primitivo. Una opción metodológica fecunda consiste, a mi parecer, en una aproximación que, por debajo de la refundición principalmente discursiva del historiógrafo, alcance, como en el mito, el sistema básico de las relaciones semántico-narrativas.

No pretendo - esto sería un disparate- trazar una frontera infranqueable entre la mentalidad nobiliaria y las concepciones clericales, ni postular una oposición irreconciliable entre los intereses de la nobleza y los de la realeza. Por supuesto, en la Edad Media alta y central, la espiritualidad cristiana penetró toda la construcción social y mental, incluido el grupo nobiliario y los valores que lo movían. Desde luego, durante la misma época, la nobleza, bajo modalidades varias que reflejaban la variedad de las capas y grupos que la componían, participó plenamente a la construcción del poder regio. Pero aun así: la leyenda heroica y el cantar de gesta están marcados, en sus estructuras narrativas profundas, por la peculiar impronta de la ética y de las preocupaciones sociales y políticas que fueron las de la nebulosa nobiliaria.

Todo esto es sabido o está ampliamente aceptado. Quizá sea menos corriente afirmar, como lo hago, que la heroicidad épica o legendaria no fue sólo una expresión, no sólo un reflejo más o menos fiel y más o menos orgánico de la cultura nobiliaria, sino que estuvo regida principalmente por una función didáctica, que los cantares y otros relatos heroicos tuvieron por meta principal la de inculcar a los jóvenes de la nobleza y recordar a sus demás miembros los principios más profundos del funcionamiento del grupo y los criterios que éste debía adoptar para seguir existiendo, defender sus intereses y perpetuar su poderío. En esto está, por la importancia de los retos que dejaron en ellos su huella, la grandísima relevancia del testimonio de los cantares y otras leyendas heroicas. 
Es fácil observar, en dicho marco teórico, que unas mismas cuestiones y valoraciones pueblan el conjunto de las producciones heroicas, tocantes tanto a la concepción del derecho como a las nociones de fidelidad o de señorío, a la relación del noble con los otros grandes poderes (Iglesia y realeza, principalmente), y otros muchos temas... Creo, sin embargo, que cada relato tuvo su singularidad semántica, que cada relato estuvo dotado de un núcleo semántico que lo vinculaba a una cuestión particular, siempre fundamental, que se le planteaba al grupo. Para decirlo muy rápidamente, el Cantar de Mio Cid está hondamente habitado por la cuestión de los criterios del honor - ¿descansa éste sobre el esfuerzo o sobre la natura?-, el Cantar del Cerco de Zamora está recorrido por la casuística del consejo y en el de Bernardo del Carpio se expresan las relaciones, no pocas veces conflictivas, entre la obediencia al rey y la solidaridad parental ${ }^{3}$.

Esto no quiere decir que me pronuncie en contra de una vinculación de los cantares o de las leyendas heroicas con la historia. Aunque, dentro de las concepciones que son las mías, más bien se trataría de una vinculación con la historiografía o con el imaginario histórico, pues muchos de estos relatos están enmarcados -aunque no siempre muy estrechamente- en un sistema de referentes históricos cuya utilidad es ante todo la de darles un estatuto histórico, esto es el estatuto cognitivo de algo que fue, de algo que aconteció en el universo de la experiencia humana, en el orden de las res gestae. Dejo este campo para otros estudiosos, subrayando simplemente que la relación entre el cantar o la leyenda heroica y la historia no es ni directa ni sencilla, sino semántica ${ }^{4}$-también lo es, por lo demás, la relación entre historiografía e historia, estando impulsada la primera, más que por el celo de alcanzar la verdad de los hechos, por la voluntad de darles sentido, esto es de servir, bajo forma de propaganda, intereses locales, sociales o políticos. Así que tampoco la aspiración del relato heroico a la historicidad redunda en contra de la tesis que su función fue esencialmente socio-didáctica: el estatuto supuestamente "histórico" de los hechos que narraba consolidaba su crédito y aumentaba su poder de persuasión.

En cuanto al Cantar (o a la leyenda) de los siete infantes de Salas ${ }^{5}$, su rasgo más notable y que lo distingue del resto del corpus heroico hispano es que el argumento está enteramente contenido en los límites de lo que llamaríamos hoy un drama familiar, o, para adoptar una terminología menos inadecuada a las nociones del tiempo, en la esfera del parentesco y, más precisamente, del parentesco entre los miembros de dos linajes aliados: el de Ruy Velásquez de Bilvestre y el de su cuñado Gonzalo Gústioz de Salas. Los testimonios más antiguos que nos brinda del relato la historiografía -el de la Estoria de España alfonsí, en sus versiones crítica $^{6}$ y sanchina ${ }^{7}$, las dos de los años 1280, y el de la Crónica general de España de $1344^{8}$ precisan cuidadosa y repetidamente los vínculos de parentesco entre los personajes: marido/ mujer, padre-madre/hijos, tío/sobrinos, hermanos, primos "cormanos", cuñados, etc. Éstos cubren las tres relaciones fundamentales del parentesco (alianza, filiación y consanguinidad), sobre las que se destaca por su especial protagonismo y dentro de las relaciones definidoras de lo que Levi-Strauss llamó el "átomo de parentesco" (hermano/hermana, marido/mujer, padre/hijo, tío materno/sobrino), el papel del tío materno ${ }^{10}$. La valoración relativa de las tres relaciones de parentesco -o si se quiere, la jerarquización de las obligaciones que inducen éstas en los parientes-y la evaluación ética del comportamiento del tío materno relativamente a sus sobrinos constituyen, en mi opinión, los temas semánticos más fundamentales de un esquema narrativo que comparten todas las versiones de la leyenda. Iré describiendo dicho esquema indicando además los datos sociales íntimamente vinculados a él en la causalidad narrativa y el significado de la Leyenda de los Infantes de Salas. 


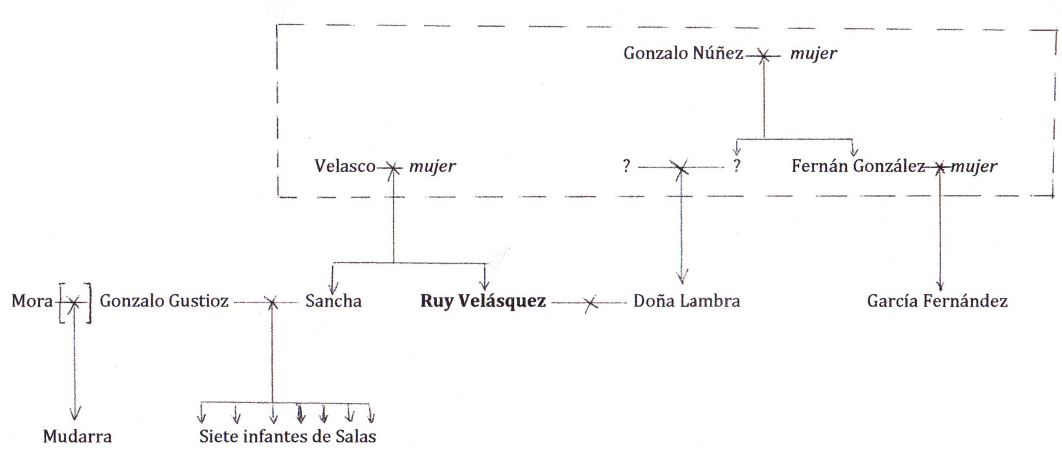

Esquema de las relaciones de parentesco en la Leyenda de los infantes de Salas

Ruy Velásquez, alto hombre del alfoz de Lara y señor de Bilvestre, casa con doña Lambra, prima hermana ("cormana") de García Fernández, conde de Castilla. Se trata de una unión que la historia antropológica califica de hipergámica y en la que un hombre se une a una mujer de mayor rango, la cual, aunque por lo general no heredera, le da acceso a una esfera social superior, abriéndole posibilidades de mejora. En el ámbito estrictamente parental, Ruy Velásquez y doña Lambra están unidos por una relación de alianza, e incluso por el acto fundador de dicha relación. A esto se limitará, durante todo el relato, la parentela creada por Ruy Velásquez. El matrimonio, en efecto, no tendrá hijos o, por lo menos, no se nos dice, a lo largo de un relato cuyo tiempo referido, añadiendo al "hecho de los infantes" la infancia de su vengador, Mudarra, dura, en la Crónica de 1344, más de dieciocho años ${ }^{11}$, que el matrimonio haya sido fecundo. Antes bien, la Crónica de 1344 afirma rotundamente lo contrario, declarando después de muerto Ruy Velásquez: "elle nõ avya ne huu filho nem filha" ${ }^{\prime 2}$. En la semántica estructural del relato, fuera de toda cronología, se trata de un matrimonio sin progenie, limitándose el parentesco fundado por los esposos a una pura relación de alianza.

En cambio, el parentesco inicial de Ruy Velásquez - el que ya existía antes de su matrimoniose extiende a otro linaje, el de Gonzalo Gústioz de Salas, mediante doña Sancha, hermana del señor de Bilvestre y esposa de don Gonzalo. También el casamiento de Gonzalo con Sancha está acorde al criterio hipergámico, pues se trasluce del relato que el marido, por muy "bueno" que fuera, no estaba a la altura social de su cuñado: "donna Sancha era casada con don Gonçalo Gustioz el bueno, que fue de Salas", reza escuetamente la Estoria de España ${ }^{13}$. Ahora bien, este matrimonio, aunque de menor rango que el formado por Ruy Velásquez y doña Lambra, le aventaja bajo el criterio de la filiación, pues ha dado lugar a una prodigiosa progenie: siete hijos, todos varones, los llamados "infantes de Salas", a los que Ruy Velásquez, como tío materno, está unido por una relación de consanguinidad. La parentela creada por Gonzalo Gústioz y doña Sancha, del todo cabal, reúne las tres relaciones fundamentales del parentesco: la alianza (entre esposos), la filiación (entre padres e hijos) y la consanguinidad (entre hermanos).

Sea o no a causa de la arrogante superioridad procreadora del matrimonio de rango social inferior, el relato se inicia con dos agresiones consecutivas llevadas a cabo por doña Lambra contra los infantes que suscitarán las mortíferas reacciones de éstos: las palabras desafiantes u ofensivas durante las bodas en Burgos, con la muerte del primo hermano de doña Lambra; 
y el episodio del cohombro lleno de sangre y de la muerte del vasallo de doña Lambra. En ambos casos es doña Lambra quien inicia el conflicto. Los intentos conciliadores del conde García Fernández y de Gonzalo Gústioz ${ }^{14}$ no aplacarán la agresividad de la tía política (o tía por alianza) hacia sus sobrinos. En este tramo del relato, la clave del devenir de los acontecimientos -y de la significación de la leyenda- está en manos de Ruy Velásquez, tío materno de los infantes.

La etnología, como también la antropología histórica aplicada tanto al estudio de la nobleza medieval como al de los cantares de gesta, suelen subrayar la importancia que tuvo en la Edad Media el tío materno en los comportamientos de la parentela aristocrática ${ }^{15}$. En el marco de la práctica de la unión hipergámica -que era el uso general y que constituye un dato básico de nuestra leyenda, ya que caracteriza los dos matrimonios que la protagonizan- la relación entre los sobrinos y el tío materno ofrecía un mutuo interés. Los sobrinos hallaban en su tío materno, más poderoso que su padre, la ayuda y el apoyo necesarios para su elevación social. El tío, por su lado, podía, mediante su hermana y sus sobrinos, ejercer su influencia sobre el linaje aliado y valerse de él. En caso de falta o de extinción de progenie, el sobrino se ofrecía como un recurso para perpetuar linaje, poder y bienes. La epopeya hispana ofrece sonados casos de esta posibilidad, como el de Bernardo del Carpio y Alfonso el Casto o, en la misma leyenda de los infantes tal como la transmite la Crónica general de 1344, el de Mudarra y Almanzor, sobre el que volveremos.

La leyenda ilustra muy tempranamente el mutuo interés que podía presentar la relación avuncular: apenas ocurrido el segundo enfrentamiento entre la tía política y sus sobrinos (el del cohombro hinchado de sangre), Gonzalo Gústioz propone a Ruy Velásquez que éstos vengan a ser algo así como sus vasallos, intentando asociar al tío materno y a sus sobrinos en la clásica relación social de reciprocidad del servicio y del beneficio:

\begin{abstract}
Sobresto dixo alli estonces Gonçalo Gustioz a Roy Blasquez: "don Rodrigo, uos auedes muy mester caualleros, ca sodes del mayor prez darmas que otro que omne sepa, de guisa que moros et cristianos uos an por ende grand enuidia et uos temen mucho; et por ende ternia yo por bien que uos siruiessen mios fijos et uos aguardassen si uos por bien lo touiessedes et uos ploguiese; et uos que les fuessedes bueno et lo fiziessedes en manera que ellos ualiessen mas por uos, ca uestros sobrinos son et non an de fazer al sinon lo que uos mandaredes et touieredes por bien". Et ell otorgol que assi serie et lo complirie ${ }^{16}$.
\end{abstract}

En el marco de esta relación feudo-avuncular es precisamente donde Ruy Velásquez va a mostrarse contra-ejemplar: abusando de la obediencia y fidelidad de sus sobrinos y vasallos, el tío materno los manda deliberadamente a la muerte, transgrediendo y traicionando a la vez la solidaridad parental y la solidaridad señorial. En esto está el primer grado de la enseñanza que brinda la leyenda de los infantes de Salas sobre solidaridad linajística. Ésta recuerda la importancia del papel social del tío materno a través de un contra-ejemplo, siendo el aleccionamiento contra-ejemplar una técnica de todo didactismo narrativo y un tópico del didactismo medieval.

Pero hay un segundo grado, más profundo, en la enseñanza linajística de nuestra leyenda, pues la contra-ejemplaridad del tío materno de los infantes de Salas cobra a su vez su significación en el marco del enfrentamiento entre los sobrinos y la esposa de Ruy Velásquez, esto es en el de un conflicto entre parientes consanguíneos y parienta por alianza. La leyenda pone a Ruy Velásquez en situación de tener que escoger entre dos obligaciones debidas a dos relaciones de parentesco, o bien de negociar un compromiso entre ambas. Concretamente, la disyuntiva impuesta a Ruy Velásquez es la de ponerse del lado de su mujer, acatando la obligación debida al vínculo de alianza, o bien de acogerse al campo de sus sobrinos, en nombre de la obligada solidaridad entre consanguíneos.

Por motivos que el relato deja del todo implícitos - ¿amor a su esposa? ¿ambición que le lleva a preservar a la prima del conde de Castilla? ¿envidia de la prolífica progenie de su cuñado? ¿culpabilidad por no conseguir lo mismo con doña Lambra?-, Ruy Velásquez, ahí está lo importante, no va a considerar en ningún momento la obligación debida a la consanguinidad. Bien al contrario, desde un principio y a lo largo de todo el relato, sin tener en cuenta las 
razones de sus sobrinos ni incluso consultarlos sobre las causas de sus repetidos conflictos con doña Lambra, Ruy Velásquez, atento sólo a las alegaciones y ruidosas demostraciones de su mujer, se muestra partidario resuelto y exclusivo de sus intereses, viniendo a erigirse en vengador de los parientes y vasallos de ésta ${ }^{17}$ hasta el punto de aniquilar a sus sobrinos. Aun en los momentos en que se ofrece una posibilidad de arreglo, Ruy Velásquez no hace más que fingir para preparar mejor el desastrado fin de sus sobrinos ${ }^{18}$. Instrumento de la alianza, incapaz de instaurar la filiación, Ruy Velásquez destroza a sus consanguíneos, acabando así con su linaje. Contraejemplo absoluto, Ruy Velásquez ilustra a contrario lo que tiene que ser: en la solidaridad linajística, la consanguinidad debe prevalecer sobre la alianza. El noble debe perpetuar el linaje generando hijos y cuidar de su consolidación cultivando la solidaridad entre consanguíneos. La alianza, desde luego, es la relación fundadora del parentesco, pero, como escribe Levi-Strauss, "el hijo es imprescindible para certificar el carácter dinámico y teleológico del paso inicial, que funda el parentesco en la alianza"19. Ahora bien, una vez conseguido el objetivo de la alianza -si es que se da el caso, lo que no ocurre en nuestra leyenda-, y llegado el eventual conflicto entre obligaciones debidas al parentesco, la alianza debe pasar por detrás de las otras dos relaciones, del todo capitales, que son la filiación y la consanguinidad y, luego, la solidaridad con el cónyuge y sus propios parientes debe pasar por detrás de la solidaridad con los hijos, si los hay, y con los consanguíneos.

El fin del relato confirma esta interpretación de la leyenda de los infantes de Salas. El que vengará a los infantes, el que, en todas las versiones de la leyenda, castigará, matando primero a Ruy Velásquez, la inobservancia de la obligada solidaridad entre consanguíneos y, matando luego a doña Lambra, la indebida primacía de la alianza, es el consanguíneo suyo Mudarra González. Y fijémonos en la supervaloración de que goza la consanguinidad a expensas de la alianza en el personaje (y, luego, en la acción) de Mudarra, pues éste no es sólo bastardo, o sea fruto de una unión carnal que, por realizarse fuera de todo contrato o sacramento, no da lugar a ningún tipo de alianza, sino que es además doblemente adulterino, eso es producto de la doble transgresión de la alianza matrimonial de Gonzalo Gústioz con doña Sancha y de la alianza espiritual que une a los fieles de una misma religión y prohíbe las uniones mixtas. En cambio, la leyenda hace de Mudarra no sólo el consanguíneo real (parental) de los infantes de Salas, como vástago biológico de Gonzalo Gústioz, sino también su consanguíneo simbólico (social) como partícipe de la solidaridad consanguínea "transnacional" ${ }^{20}$ de la nobleza, siendo su madre, aunque mora, "fija dalgo" 21.

Pero la Crónica de 1344 añade a este desenlace altamente significativo un dato que hace de Almanzor el contramodelo de Ruy Velásquez. En esta versión de la leyenda, en efecto, la madre de Mudarra es hermana del caudillo cordobés ${ }^{22}$, lo que hace de Almanzor el tío materno del joven bastardo. Pero un tío materno del todo ejemplar y cumplidor, quien, valorando la consanguinidad hasta confundirla simbólicamente con la filiación, considera a su sobrino como a su hijo ${ }^{23}$ bien que le permita salir en busca de su padre biológico proveyéndolo de hombres y recursos y ayudándole así a cumplir con su deber ${ }^{24}$.

Consideraré pues que la semántica de la leyenda de los siete infantes de Salas está regida en su lógica narrativa profunda por una enseñanza tocante a solidaridad linajística. Ésta prescribe lo que debe ser el papel del tío materno, afirma la primacía de la obligación debida a la consanguinidad en caso de que ésta entre en conflicto con la obligación debida a la alianza, y fija una jerarquía general de las relaciones de parentesco en que la filiación y la consanguinidad están por encima de la alianza. Afirmado esto, también está claro que dicha enseñanza se formula sobre un fondo de valoraciones que cubren casi por entero el campo de la ideología nobiliaria. Sin adentrarme en temas que otros van a tratar, señalaré tres aspectos a mi parecer muy relevantes.

El primero es la ausencia de protagonismo clerical e incluso de preocupación religiosa en la leyenda. Ésta es particularmente radical en la Estoria de España, por mucho que, probablemente bajo la influencia de los Lara, la Crónica de 1344 cristianice, mediante un pomposo bautizo, a Mudarra, antepasado del linaje ${ }^{25}$. Con todo, no se alude al sacramento 
eclesiástico cuando las bodas de Ruy Velásquez, ni media ningún sacramento, por supuesto, en la unión de Gonzalo Gústioz con la mora. La venganza y la crueldad -la tremenda crueldad de doña Sancha en la Crónica de 1344, que ansía beber la sangre de su hermano ${ }^{26}$ - no son objeto de crítica. Las bondades que Gonzalo Gústioz, en sus siete llantos, atribuye a sus hijos en la misma obra (uno es buen guerreador, otro buen "jugador de tablas", otro buen cazador, etc.) no dan cabida a ninguna virtud cristiana (Lindley Cintra, 1961: III, 145-148). Por supuesto, esto se compagina perfectamente con el desprestigio que sufre en nuestra leyenda la alianza, parentesco "espiritual" tan altamente valorado por la Iglesia a partir del siglo XII ${ }^{27}$. El segundo rasgo es la exaltación de las figuras antropológicas del hijo menor (Gonzalo González) y del bastardo (Mudarra), ilustraciones bien conocidas, la primera, de la perennidad e incluso del mejoramiento en el tiempo de las aptitudes procreadoras del noble, ya que el último de los hijos es también el mejor dotado naturalmente, y la segunda de la eficacia de la pura cópula carnal, sin necesidad de ninguna mediación sacramental ${ }^{28}$. Estamos tocando aquí niveles muy profundos, primordiales, de la mentalidad nobiliaria.

En fin, el hecho de hacer de los infantes los vasallos de su tío Ruy Velásquez -junto con otras manifestaciones de una casuística del vasallaje (entre Ruy Velásquez y el conde García Fernández o entre un criado y doña Lambra)- da lugar a una evaluación contrastiva de varios protagonistas en el marco de las obligaciones recíprocas creadas por el compromiso vasallático. Esto último acaba cobrando una importancia primordial -probablemente debida, a su vez, a la situación que era la de los Lara frente a Alfonso XI- en la versión de la leyenda contenida en la Crónica general de 1344, donde Ruy Velásquez, más que el de un mal tío materno, desempeña el papel de traidor, papel del que acaba siendo la expresión antonomástica ${ }^{29}$.

Todos estos elementos de un universo mental conviven y laten en una leyenda de esencia nobiliaria cuyo núcleo es el de una enseñanza tocante al papel del tío materno en el destino del linaje y a la jerarquía de las obligaciones debidas a las tres relaciones fundamentales del parentesco (alianza, filiación y consanguinidad).

\section{Notes}

1 Véanse Georges MARTIN, Les Juges de Castille. Mentalités et discours historique dans l'Espagne médiévale, Paris, Annexes des Cahiers de linguistique hispanique médiévale, 6, 1992, p. 251-316 y "Noblesse et royauté dans le De rebus Hispaniae (livres 4 à 9)", Cahiers de linguistique et de civilisation hispaniques médiévales, 26, p. 101-121 [ahora en internet].

2 Mal llamado por ser formalista y reductor. En realidad se trata de un verdadero proceso de "reescritura" historiográfica dentro del que las leyes del discurso histórico que emana de la Iglesia y de la Corona desvirtúan los valores nobiliarios y los sustituyen por los de la ética regio-clerical. Véase, sobre el tema, Patricia ROCHWERT-ZUILI, "Recherches sur la mise en prose des poèmes héroïques dans l'Histoire d'Espagne. Le Cantar primero du Poème du Cid dans la Chronique de vingt rois", Cahiers de linguistique hispanique médiévale, 22, p. 131-160 [ahora en internet].

3 Para un estudio más detenido, véase Georges MARTIN, "La geste", en Jean CANAVAGGIO (dir.), Histoire de la littérature espagnole, Paris: Fayard, 1993, 1, p. 43-73 y "Le récit héroïque castillan (formes, enjeux sémantiques et fonctions socio-culturelles)", en Georges MARTIN, Histoires de l'Espagne médiévale (historiographie, geste, romancero), Annexes des Cahiers de linguistique hispanique médiévale, 11, p. 139-152 [ahora en internet].

4 La mejor crítica de la "historicidad" pidalina aplicada al Cantar de los infantes de Salas me parece ser la de Julio ESCALONA, "Épica, crónicas y genealogías. En torno a la historicidad de la Leyenda de los infantes de Lara", Cahiers de linguistique hispanique médiévale, 23, p. 113-176, aunque la interpretación histórica de la leyenda propuesta luego por Escalona no sea convincente, puesto que invierte, como las procedentes del conocido historicismo neo-tradicionalista, causas y efectos, tomando por primicias o determinaciones de la leyenda las que fueron explotaciones sociales (localistas o genealógicas) posteriores a su elaboración. Por otra parte, y contrariamente a lo que pretende Escalona (p. 115), Ruy Velásquez nunca aparece en la Estoria como "señor de Lara" (lo eran los mismos condes de Castilla) sino como un "alto omne natural dell alffoz de Lara" y "señor de Biluestre" [Ramón MENÉNDEZ PIDAL (ed.), Primera crónica general de España, 2 vol., Madrid: Gredos (Seminario Menéndez Pidal, Fuentes cronísticas de la historia de España, 1), 1955 (reed. 1977), II, p. 431ª ], lo que quita mucha fuerza a su teoría de una rivalidad entre Salas y Lara. Para la crítica del pidalismo, véase también René COTRAIT, Histoire et poésie. Le comte Fernán González. Genèse de la légende, Grenoble: Allier, 1977, p. 170-177. 
$5 \mathrm{Al}$ contrario del Cantar del rey don Fernando (o del Cerco de Zamora) y del Cantar de Bernardo del Carpio, la leyenda de los infantes de Salas no da lugar a que los redactores de la Estoria de Espana alfonsí aludan a "cantares" o a "fablas de gesta". Sólo evocan "la estoria". Pero ocurre lo mismo con el Cantar de Mio Cid... (MARTIN, "Le récit héroïque castillan ...”, p. 140-141, n. 7).

6 Manuel DE LA CAMPA GUTIÉRREZ (ed.), La Estoria de España de Alfonso X.Estudio y edición de la versión crítica desde Fruela II hasta la muerte de Fernando II, Málaga: Universidad de Málaga (Analecta Malacitana, Anejo 1xxv), 2009, p. 334-350.

7 MENÉNDEZ PIDAL, Primera crónica general, II, p. 431-448.

8 Luís Filipe LINDLEY CINTRA (ed.), Crónica geral de Espanha de 1344, Lisboa: Academia Portuguesa da Historia, 1951-1961, III, p. 112-171.

9 Claude LÉVI-STRAUSS, Anthropologie structurale, Paris: Plon, 1958, p. 56): "Pour qu'une structure de parenté existe, il faut que s'y trouvent présents les trois types de relations familiales toujours donnés dans la société humaine, c'est-à-dire: une relation de consanguinité, une relation d'alliance, une relation de filiation".

10 El elemento o átomo de parentesco reúne cuatro términos (hermano, hermana, padre, hijo) o cuatro relaciones (hermano-hermana, marido-mujer, padre-hijo, tío materno-sobrino). LÉVI-STRAUSS, op. cit., p. 56: "Nous voyons donc que l'avunculat pour être compris, doit être traité comme une relation intérieure à un système, et que c'est le système lui-même qui doit être considéré dans son ensemble, pour en apercevoir la structure. Cette structure repose elle-même sur quatre termes (frère, soeur, père, fils) unis entre eux par deux couples d'oppositions corrélatives, et tels que, dans chacune des deux générations en cause, il existe toujours une relation positive et une relation ngative. Qu'est-ce maintenant, que cette structure et quelle peut être sa raison? La réponse est la suivante: cette structure est la structure de parenté la plus simple qu'on puisse concevoir et qui puisse exister. C'est, à proprement parler, l'élément de parenté". Más lejos, escribirá "atome de parenté" (p. 58). Claude Lévi-Strauss mantendrá esta última fórmula en Anthropologie structurale deux (Paris: Plon, 1973, p. 103-135), donde recordará con particular vigor las cuatro relaciones constitutivas del átomo de parentesco ya expuestas en Anthroplogie structurale (p. 50-51): “Ce que je proposais d'appeler atome de parenté, c'est-à-dire le système quadrangulaire de relations entre frère et soeur, mari et femme, père et fils, oncle maternel et neveu, était donc, dans ma pensée, la structure la plus simple qu'il soit donné de concevoir et parfois même d'observer" (p. 105).

11 Dieciocho años duran los sufrimientos de Gonzalo Gústioz hasta que Mudarra le venga, devolviéndole su honra y su prosperidad : "E durou dezoyto ãnos [Gonçalo Gustiuz] em esta catividade, ataa que lhe Deus pos consselho" (LINDLEY CINTRA, op. cit., III, 152).

12 LINDLEY CINTRA, op. cit., III, p. 170.

13 MENÉNDEZ PIDAL, op. cit., II, p. 431.

14 "Mas el conde Garçi Fernandez, que era sennor et era y en Burgos, et Gonçalo Gustioz, padre de los infantes, luego que sopieron aquella pelea, fueron pora alla, et metieronse entrellos et departieronlos, que no ouo y estonces otro mal ninguno" (ibid., p. 432b); "Et don Gonçalo ueno y otro dia otrossi con sus vii fijos, et ouieron su fabla entre Barbadillo et Salas sobre razon de la desondra de donna Lambra que los vii infantes le fizieran; e pusieron su amor unos con otros, et metieronse estonces los infantes en mano de su tio don Rodrigo, que ell catasse aquel fecho por quien se leuantara, et que el fiziesse y aquello que touiesse por bien et fuesse derecho" (ibid., p. 434b).

15 LÉVI-STRAUSS, Anthropologie structurale, p. 37-62. En cuanto a la sociedad medieval y a los cantares, Lévi-Strauss citaba los trabajos de G. E. HOWARD, A history of matrimonial institutions, 3 vol., Chicago: Chicago University Press, 1904, de William Oliver FARNSWORTH, Uncle and nephew in the old french chanson de geste, New York: Columbia University Press, 1913, y de Léon GAUTIER, La Chevalerie, Paris: Arthaud, 1960. También habría que mencionar las aportaciones de Marc BLOCH, La Société féodale, Paris: Albin Michel, 1939, rééd. 1994, p. 183 sq., Reto R. BEZZOLA, "Les neveux",en Mélanges Frappier, Genève: Droz, 1970, p. 89-114, Robin FOX, Anthropologie de la parenté. Une analyse de la consanguinité et de l'alliance, Paris: Gallimard, 1972, p. 230 sq., Georges DUBY, Hommes et structures du Moyen Âge, Paris: Mouton, 1973, p. 275-278, Alice PLANCHE, "Roland fils de personne", en Charlemagne et l'épopée romane, Paris: Les Belles Lettres, 2 t.; 2, p. 595-604, Yves ROGUET, “Des neveux”, en L'Hostellerie de pensée, Paris: Presses de l'Université de Paris Sorbonne, p. 383-390, y Despina ION, La parenté dans Garin le Loheren et Gerbert de Mez, Étude littéraire, linguistique et anthropologique, tesis doctoral (dactil.), Universidad de Nancy II, 1999.

16 MENÉNDEZ PIDAL, op. cit., p. 433a. La versión crítica, habitualmente más concisa que la sanchina, subraya aquí el vínculo de consanguinidad: "Et Rruy Velazquez dixol que le plazie mucho con ellos e que les farie toda onrra que el pudiese commo a sus sobrinos e a su carne" (DE LA CAMPA, op. cit., p. 336).

17 Después de muerto Álvar Sánchez, primo hermano de doña Lambra, a manos del infante Gonzalo González: "Donna Llambla, quando lo oyo, començo a dar grandes uozes, llorando muy fuerte, et diziendo que nunqua duenna assi fuera desondrada en sus bodas como ella fuera alli. Roy Blasquez, quando aquello sopo, caualgo a grand priessa, et tom un astil en la mano, et fuesse pora alla do estauan; et 
quando llego a los vii infantes, alço a arriba el braço con aquell astil que leuaua, e dio con ell un tan grand colpe en la cabesça a Gonçalo Gonçalez que por cinco lugares le fizo crebar la sangre" (MENÉNDEZ PIDAL, op. cit., p. 432). Después de muerto por los infantes el vasallo enviado por doña Lambra para macular con sangre el pecho de Gonzalo González: "Estonces donna Llambla, quando sopo que uinie don Rodrigo, cato et quandol uio entrar por el palatio, fuse pora ell toda rascada et lorando mucho de los oios, et echose a sus pies pidiendol merced quel pesasse mucho de la desondra que auie recebida de sus sobrinos, et que por Dios et por su mesura quel diesse ende derecho. Dixol estonces don Rodrigo: 'donna Llambla, callad, non uos pese, et soffrituos, ca yo uos prometo que tal derecho uos de ende que tod el mundo aura que dezir dello"” (ibid., p. 434b).

18 Cuando, después de las heridas de unos y otros consecutivas a la muerte de Álvar Sánchez, o bien después de la muerte del vassallo de doña Lambra, Gonzalo Gústioz pone a sus hijos en poder de su tío (ibid., p. 433a y 434b); o bien cuando, muerto Gonzalo Sánchez, vasallo de Ruy Velásquez, por Gonzalo González en un intento de defender éste a su ayo Muño Salido, el tío de los infantes finge hábilmente aceptar la "caloña" que le ofrecen sus sobrinos (ibid., p. 438a).

19 LÉVY-STRAUSS, Anthropologie structurale, p. 57.

20 Entiendo "nación” en el sentido medieval (étnico o religioso) de natio.

21 "Et dixol Almançor [a Gonçalo Gustioz]: 'Pues dezirtelo e yo. Roy Blasquez me enuia dezir que te descabesçe; mas yo, por que te quiero bien, non lo quiero fazer,mas mandarte he echar en prision'. Et fizolo assi. Desi mando a una mora fijadalgo quel guardasse yl siruiesse yl diesse lo que ouiesse mester. Et assi aueno a pocos de dias que don Gonçalo yaziendo en aquella prision, et aquella mora siruiendol, que ouieron de entender en si et amarse ell uno al otro, e manera que don Gonçalo ouo de fazer un fijo en ella, a que llamaron despues Mudarra Gonçalez" (MENÉNDEZ PIDAL, op. cit., p. 435b). DE LA CAMPA (op. cit., p. 349): "era muger byen fija dalgo segund la su ley de los moros".

22 LINDLEY CINTRA (op. cit., III, p. 148a): “Almãçor mandou chamar hua iffante, sua irmaã, que era muy fremosa e muy mãnceba e era donzella virge...", etc.

23 LINDLEY CINTRA (op. cit., III, p. 152-153): “Conta a estorya que a infante, irmaã del rey Almançor, quando se sentyo prenhe, vyo que podrya viir a dampno se o negasse a seu irmaão el rey Amançor e ouvelhe a contar toda sua fazenda. E Almançor, quando o soube, prouguelhe muito. E mandouha muy bem guardar e fazer quanto prazer pode ataa que pario seu filho. E a Almançor prougue muyto cõn elle e mandoulhe logo catar sete amas pera seer melhor criado, escolhendo aquellas que avyam melhor leite E Almançorbvyao cada dya e pagavasse delle tanto que se nõ pagaria mais de huu filho, se o ouesse, ca Almançor nom avya nem huu filho". Almanzor está dispuesto incluso a hacer de Mudarra su heredero (ver texto citado en la nota siguiente).

24 LINDLEY CINTRA (op. cit., III, p. 155): “Dom Mudarra Gonçalvez [...] foisse pera seu tyo Almançor e beyjoulhe as maãos e disselhe: 'Senhor, vossos mouros me doestam em vossa casa e me dize que nõ ey padre. E eu quero hyr a buscallo. E, se o ouver boo e honrrado, tornarvos hei a veer. E, se for outro que nõ seja honrrado ne d'alto sangue, nunca me mais veeredes em vossa casa'. E Almanzor lhe disse: 'Vos avedes boo e honrrado padre, qual sabe em toda Espanha. E nunca vos esso tal dira nem huu que lhe eu nõ mande cortar a cabeça, ca eu nõ ey outro filho que herde despois mynha morte se nõ vos'. E elle disse que em ne hua guisa nõ ficarya, ata que hua vez, nõ fosse saber que era seu padre. E Almançor, quando vyo a sua vootade, disselhe que le querya dar trezentos cavalleyros e que os pagaria por sete annos. [...] E deulhe grande peça de seu aver; e deulhe adaiis, que o guyassem".

25 LINDLEY CINTRA, op. cit., III, p. 162

26 Doña Sancha sueña primero que bebe la sangre de su traicionero hermano y se dispone luego a hacerlo de verdad cuando Mudarra lo trae cautivo (LINDLEY CINTRA, op. cit., III, p 156-157 y 169).

27 En este sentido, los estudios de Anita Guerreau. También, por supuesto, Georges DUBY, Le chevalier, la femme et le prêtre, Paris: Hachette, 1981.

28 También sobre esto, DUBY, Le chevalier, la femme et le prêtre.

29 El calificativo, asociado primero sistemáticamente al nombre del protagonista -“o treedor de Ruy Vaasquez", (LINDLEY CINTRA, op. cit., III, p. 151, 156, 160, 161, 162)-, acaba por sustituir del todo al nombre -“o treedor" (LINDLEY CINTRA, op. cit., III, p. 163, 164, 165, 166, 167)-.

\section{Notes}

* Este estudio se presentó en el I congreso internacional "Los siete infantes de Lara. La historia frente a la leyenda" celebrado en Salas de los Infantes los 13-15 de julio de 2011. Se espera su publicación en las actas de dicho congreso. 


\section{Pour citer cet article}

Référence électronique

Georges MARTIN, « La leyenda de los Siete infantes de Salas y su enseñanza sobre solidaridad linajística », e-Spania [En ligne], 14 I décembre 2012, mis en ligne le 18 janvier 2013, consulté le 08 mars 2013. URL : http://e-spania.revues.org/22032 ; DOI : 10.4000/e-spania.22032

\section{À propos de l'auteur}

Georges MARTIN

Université Paris-Sorbonne, CLEA (EA 4083), AILP (GDRE 671, CNRS)

\section{Droits d'auteur}

(C) e-Spania 